\title{
Factors influencing students' physical science enrolment decision at the University of Education, Winneba
}

\author{
Taale ${ }^{10}$, K. D.
}

\begin{abstract}
The research explored the decisions of science students in the University of Education, Winneba (UEW) to enroll in science courses, particularly physical science, as a course or major programme. The study used a modified 'multiple worlds' model to investigate how the various worlds of the students influenced their science subject choice. All science students of UEW in the 2008/2009 academic year constituted the population from which a sample of two hundred and sixteen (216) students made up one hundred and forty-seven (147) males and sixty-nine (69) females was drawn. Purposive sampling using intact group technique was used to sample the respondents. Two equivalent forms of questionnaire designated as PSQ (for physical science students) and BSQ (for biological science students) were used to collect data on the students' demographic characteristics as well as their perceptions of influence from their school, family, peer, and societal worlds which impact on their choice of subject. The study revealed that students making different subject choices (physical or biological science) reported similar experiences and conceptions, which did not generally inspire the choice of physical science. Students who chose physical science explained the source of their motivation in terms of high self-concept and perception of selfefficacy especially in mathematics, as well as, availability of resources of peer cultural and social capital objectified in course materials such as books, hand-outs, notes and socioemotional factors such as encouragement, pieces of advice among others. Students also reported building enough self-confidence to enrol in physical science by the encouragement they received through informal contact with physics lecturers.
\end{abstract}

Keywords enrollment in science courses, students' enrolment decisions, physical science, subject choice

\section{Introduction}

Over the years, especially in recent times, there has been persistent expression of concern from several quarters, including the media, over the appalling performance of students in science subjects, with special mention of physics, in second cycle schools. The University of Education, Winneba was established with the mandate of solely training teachers for all levels of education in the country. Therefore any problem that has a bearing on the number and quality of teacher production brings it (UEW) into focus and any attempt at addressing such a problem without factoring UEW into the scheme of things will be a mere cosmetic approach at solving the problem. The research was prompted by the increasing reluctance of students to enroll in science courses, particularly physical science.

Science education is considered to be in crisis not only in Ghana but globally. The cause of this is identified as the fall in number of students taking Physics and Chemistry. While the numbers taking Physics and/or Chemistry are falling at higher levels of education, numbers taking Biology are much higher and fairly steady. According to Global Science Forum Report (2005) there is a decline in the number of university graduates up to $30-50 \%$ over the last 8 - 10 years in Physical Sciences globally and the causative factors involved are complex. This

${ }^{10}$ Dr. Taale, K. D. is a Senior Lecturer in the Department of Physics Education, University of Education, Winneba. Email: ktaale@yahoo.com/kdtaale@uew.edu.gh 
persistent decline has generated concerns in many countries, including Australia and the Western World (Dekkers \& Delaeter, 2001; Bolstad \& Hipkins, 2005; Smithers \& Robinson, 2006), Canada (Bordt, De Broucker, Harris \& Zhang, 2001), India (Garg \& Gupta, 2003), Japan (Goto, 2001), the USA (National Science Foundation, 2002). The increasing reluctance of students to choose science courses, and physical science courses in particular, have implications not only for the health of scientific endeavour in the countries, but for the scientific literacy of future generations.

Attempts to identify the underlying causes of this trend have for the most part involved quantitative analysis of students' enrolment rationales (Woolnough, 1994) and their attitudes to science (Ramsden, 1998). Other studies have analyzed the background factors associated with enrolment decisions (Fullarton \& Ainley, 2000). Although these approaches were unable to clarify just how student's decision about further science study are influenced by attitudes or backgrounds, they established a number of important statistical relationships (Lyons, 2003). Some reasons adduced have shown that students choosing Physical science courses tend to explain their decisions in terms of career aspirations (Fullarton \& Ainley, 2000); perception (Palmer, 1999); disaffection in students for the subject (Bennett, 2001; Goodrum, Hackling \& Rinnie, 2001; Osborne \& Collins, 2001); as a subject and the way Physics is taught (Anamuah-Mensah,1995); strategic needs, such as opportunity for future study or careers (Ainley, Robinson, Have-Beavis, Elsworth, \& Fleming, 1994); Barnes, 1999); intrinsic reasons for choosing biology, such as interest and enjoyment (Fullarton, Walker, Ainley, \& Hillman, 2003); and students' interpersonal environment, which include interactions with peers and lecturers (Whitt, Edison, Pascarella, Terenzini, \& Nora, 2001; Nora, 2001; Chepchieng, 2004; Garza \& Landeck, 2004); among others. Some researchers have suggested that external issues, such as perceptions of the low status of science careers, and the culture of school science itself were considered as the most cogent single forces acting against the choice of physical science courses (Osborne \& Collins, 2001; Lindah, 2003). Despite the revealing nature of these studies, however, they were carried out in foreign countries and in socio-cultural settings most part of which does not apply to the context of the present study.

\section{Statement of the Problem}

Student enrolment in science subjects, particularly physical science in the University of Education, Winneba (UEW) has consistently been comparatively low over the years. Among all the main departments in the University (UEW.), Science Department makes one of the least, if not the least student admissions every year, even after the introduction of a remedial programme up to the 2008/2009 academic year, to upgrade the pre-entry knowledge of the majority of the students who fail the entrance examination, in order to attract more students. This consequently affects the number of students opting for either biological science or the physical science with the latter having a relatively awful patronage. What is more, a number of the physical science students major in chemistry, leaving a small percentage to graduate with Physics major.

In the 2000/2001 academic year, out of one hundred and fifteen (115) students that enrolled for the science programme, only thirty students $(26.1 \%)$ opted for Physics. In the final year the number had decreased to ten (10). The 2001/2002 academic year had fifty (50) students out of which ten constituting 20\%, registered for Physics, but the percentage came down to $18 \%$ in the final year. In 2002/2003, the total number was one hundred and thirty-five (135) out of which twenty-seven (27) (that is 20\%) were for physics and in 2003/04 academic year the total number was one hundred and forty-nine (149) out of which eleven (11) (7.3\%) opted 
for Physics. Even with the direct admission introduced in 2006/07 academic year where Senior High School students were admitted without being made to write entrance examination, in addition to mature students (mostly professional teachers) who passed an entrance examination, out of the one hundred and fifty-one (151) science students admitted, only eighteen (18), $12 \%$ opted for physical science.

The shortfall in the number of physics teachers could have serious consequences for the nation because the development of every nation is driven by the advancement in science and technology education, and Physical science is a central pillar around which such advancement strives. There is therefore the need to investigate how students make their science subject enrolment decision.

\section{Research Questions}

The following two research questions guided the study:

i. How does learners' perception of physics as a subject, influence their physical science enrolment decision?

ii. What is the role of peer influence in students' choice of physical science?

\section{Methodology}

\section{The Qualitative Research Approach}

In this study, both qualitative and quantitative methods of gathering and analysing data were used. This was considered necessary because the aim of the research was to try and replicate the findings made by other people (mostly foreign) on students' physical science enrolment decision, in the Ghanaian setting and to add new findings, if any, to the existing literature. The qualitative methods were therefore needed to explore for pieces of information that could not be elicited quantitatively, and reported as such, while quantitative methodology was used in 'authenticating' findings on the topic in the present context.

\section{Research Design}

This is a case study 'borrowed' heavily from data analysis technique employed in causalcomparative study. In effect, the study fundamentally compared the perception of two different independent groups, which were students enrolled in physics and those enrolled in biology to understand the overall influence on students' enrollment decision.

\section{Population and Sample}

The target population comprised of past and present science students of the University (UEW), but the accessible group was mainly continuing level 100-300 students, Physics and other science lecturers in UEW (see Table 1).

Table 1 Detailed Sample Statistics

\begin{tabular}{|c|c|c|c|c|c|c|c|c|c|c|}
\hline \multirow[b]{3}{*}{ Students } & \multicolumn{5}{|c|}{ Planned } & \multicolumn{5}{|c|}{ Actual } \\
\hline & \multicolumn{2}{|c|}{ Male } & \multicolumn{2}{|c|}{ Female } & \multirow[b]{2}{*}{ Total } & \multicolumn{2}{|c|}{ Male } & \multicolumn{2}{|c|}{ Female } & \multirow[b]{2}{*}{ Total } \\
\hline & $\mathrm{N}$ & $\%$ & $\mathrm{~N}$ & $\%$ & & $\mathrm{~N}$ & $\%$ & $\mathrm{~N}$ & $\%$ & \\
\hline 100 & 159 & 74 & 55 & 26 & 214 & 121 & 73 & 45 & 27 & 166 \\
\hline 200 & 113 & 75 & 38 & 25 & 151 & 90 & 73 & 33 & 27 & 123 \\
\hline 300 & 108 & 69 & 48 & 31 & 156 & 102 & 69 & 45 & 31 & 147 \\
\hline Total & 380 & & 141 & & 521 & 313 & & 123 & & 436 \\
\hline
\end{tabular}

Purposive sampling technique using intact group was used in selecting students who responded to the questionnaire. This was considered necessary because the science 
department has a relatively small number of students at the various levels compared to other departments in the University, and also the expectation that it was not all questionnaires that would be returned. A total of 436 students constituting $84 \%$ of total student population, $\mathrm{n}=521$, was sampled. These were the total number of students who were present at lectures at the various times when the questionnaires were distributed.

For the 2005/06 (Level 300) cohort of students, 72 completed questionnaires were received from a total of 147 distributed, a response rate of 49\%; the 2006/07 (Level 200) group of 123 students returned 56 questionnaires, which represented a $45 \%$ response rate while the 2007/08 (Level 100) cohort returned 88 making up 53\% of 166 distributed. The overall returned rate was $50 \%, \mathrm{n}=436$ (all figures were rounded off to 1 decimal place). Analysis of variance (ANOVA) and t-test, used to compare the demographic data on students at the various levels, as well as, on the basis of their course of study (physical science and biological science), indicated that the demographic profiles of each set of respondents were representative of their respective cohorts and that the 2005/06 year group was not different from the 2006/07 and 2007/08 year groups and the 2006/07 year group was not different from the 2007/08 year group. However, females constituted approximately $32 \%$ of the sample. Though this figure was higher than the number of females in the target population, that is, $28 \%, \mathrm{n}=512$, female representation seemed low. This perhaps confirmed the findings of Anamuah-Mensah (1995) that female participation in education decreases sharply as one climbs the education ladder.

Therefore, the data can be considered representative of the group as a whole, and where applicable the data collected from all the students have been combined to give a larger cohort for analysis.

\section{Research Instrument}

Two equivalent or parallel forms of questionnaire designated as Physical Science Students' Questionnaire (PSQ), and Biological Science Students' Questionnaire (BSQ), were developed. The questionnaires generally sought students' perception of influence from their school, family, peer, and societal worlds which impact on their choice of subject. The decision to focus primarily on students' perception of their world and their deliberation was made for two reasons. First it was assumed that the vast majority of students in this study ultimately made their own enrolment decisions based on their perception hence the degree to which their perception varied from those for example of their parents and peers was largely irrelevant to the study. Levy, Wubbels, Brekelmans and Morganfield (1997) argued in their investigation of students' perception of the classroom experiences, such perception represents the reality for student regardless of whether they are supported by external observers. Secondly students' perception has been shown to be reliable and valid comparing well with those of experienced observers (Levy et al., 1997).

Each of the questionnaires was made up of a total of 43 items. The items on the PSQ and BSQ (Appendices A and B) consisted of both unstructured items with spaces for 'free response', and structured items with fixed a range of alternate responses to which students responded on five-point Likert scale. A 5-point Likert scale was used due to its apparent appropriateness for this study because the study in part, compared gender' perceptions of physics by the research subjects across contextual variables such as school or institutional characteristics, peer influence among others. The categories on the scale includes, 'Strongly agree to Strongly disagree', Very effective to poor', Very close to Apathetic', 'Strongly approve to Strongly disapprove', Very often to Never', and 'Well above average to Well below average'. For each item, students indicated their response by marking the appropriate box corresponding to their view. To ensure the instruments were credible for a sound interpretation to be made on the response they drew, the core items of the instruments were 
adapted from previous quantitative research works, to establish construct validity. Secondly, evidence of convergence was obtained through triangulation (multiple methods to data collection) to enhance validity. The items on the questionnaires (PSQ and BSQ) under the variables; 'Influence from peer(s)', 'Influence within Students' Family' and 'Influence within society' were largely open. The responses to these items were transcribed in three ways: influence that favoured physical science enrolment, influence that neither favoured nor discourage physical science enrolment and influence that discouraged physical science enrolment. These were arbitrarily assigned the values of 3,2 and 1 respectively. Though the scoring seemed arbitrary, it corresponds to the interpretation of the structured item on the Likert Scale, where the highest mean values above the neutral value for example were considered to be favourable to physical science enrolment. These responses together with those under the variables, 'Students' Perception of Physics as a subject' and 'Students' view on teaching and learning of physics in the University (UEW) whose items were largely structured were subjected to Cronbach Alpha test of reliability in a pilot study. The pilot test involved a sample of forty-eight (48) biology and physics students. This yielded a reliability coefficient ranging from 0.45 to 0.78 .

\section{The 'multiple worlds' theoretical model}

The study adapted the modified 'multiple worlds' theoretical model by Lyons (2003). The 'multiple worlds' model was originally developed by Phelan, Davidson \& Cao (1991) to investigate influences within the student family, peer and school worlds. The adapted model used in the present study is a 'hybrid model' from the original model developed by Phelan et al (1991) and the modified version by Lyons (2003). Two modifications were made to the Lyons (2003) model, while retaining the core idea of the original model in order to make it suitable for the context of this study.

In their transitions between worlds of family, school science, peer and the society, students' are required to negotiate structural, attitudinal and dynamic features of the culture of each world. First, society was introduced to absorb and replace the 'mass-media' world included by Lyons (2003) (Figure 1), being aware of the influence that recognition and value placed on knowledge of science and its application, scientist, and science related professions by society, could have on students' interest as suggested by other research (Lipps, 1999); the gendering of physics by society (Anamuah-Mensah, 1995; Jones, Howe, \& Rua, 2000), and the assertion that the mass-media content is a "socially created product"' (Gallagher, 2004). 


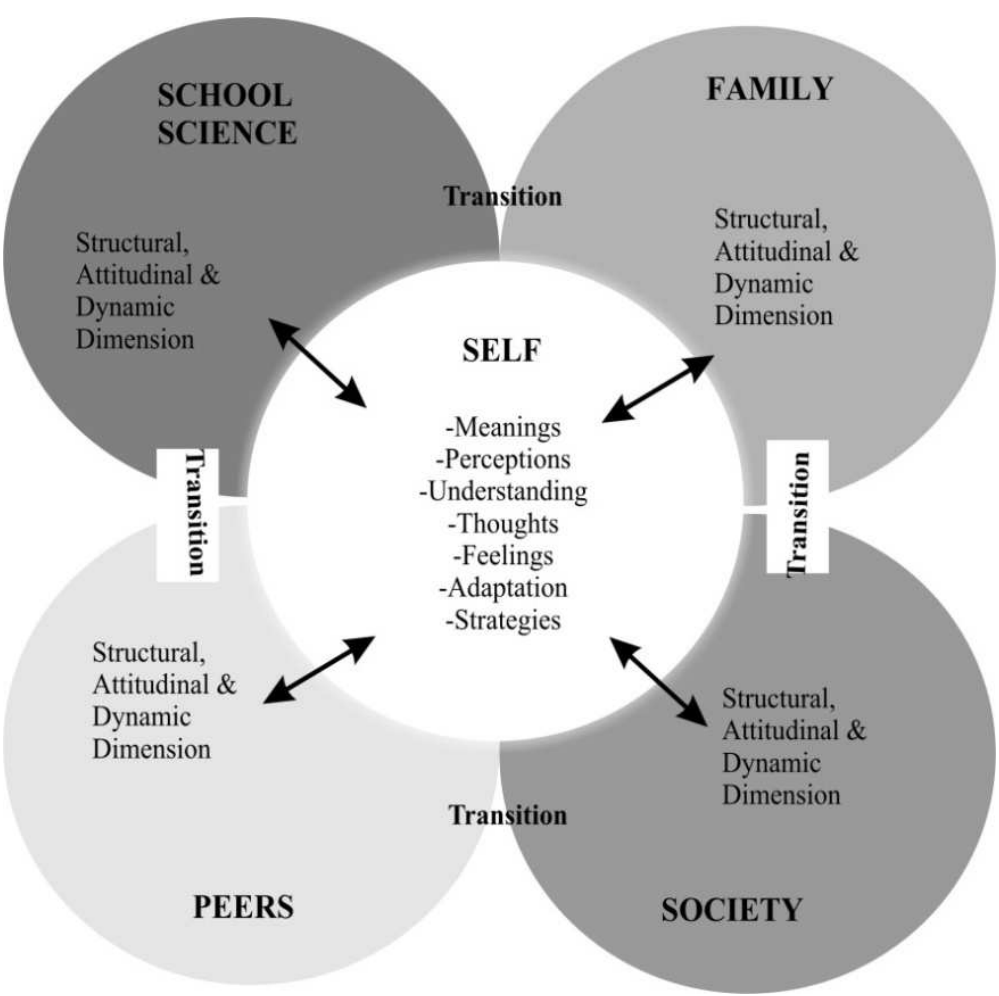

Figure.1 The theoretical model of students' multiple worlds (Source: Phelan, Davidson \& Cao, 1991 and Lyons, 2003).

Secondly, some of the structural characteristics of the worlds were redefined to include variables that were considered relevant to the study but not used in the previous studies due to circumstantial differences. For example, the school world was defined to be structured on the basis of curriculum guidelines related to the content, pedagogy of physics, and subject prerequisites only, for the study because the hindrance to the choice of physics due to the other variables included in Lyons's model such as timetable restrictions, are not applicable.

Again, the Science Department of the University (UEW) does not have any restriction that compulsorily restrains students from enrolling into physical science. All students who are admitted into the department make their own enrolment decisions perhaps based on perception of their own abilities. Therefore, subject prerequisite as defined in the context of this study is more of a perceptional phenomenon related to individual students' rating of themselves rather than a tangible variable that it was considered to be in the Lyons (2003) model. Structures in the peer worlds have been redefined to include membership of halls of residence, ethnic associations and faculty associations, among others. Though there may be no characteristic beliefs, values and attitudes that are shared by members within these structures that favours physical science enrolment or otherwise they nonetheless form the world of students and facilitate the formation of peer relationships, which have been implicated in students' subject choice decisions.

Analysis of both the qualitative and quantitative data were carried out to determine factors affecting students' choice of physical science as individual factors and as combination of factors. The qualitative data were analysed using the Statistical Package for Social Sciences (SPSS). Students who did not respond to a specific question were removed from an aggregate analysis, but not from the study. 


\section{Results and discussions}

Research Question 1 'How does learners' perception of physics as a subject, influence their physical science enrolment decision?'

Concerning choice of science subject, Lyons (2003) reported that students' experience with the subject determine their predisposition towards it. Students who have positive experience with the subject will have favourable perception of the subject and most likely enroll in it while those who have negative experience with the subject will have negative perception of the subject and most likely avoid it. Thus, students' relative experiences and subsequent perception of science dichotomize them along various science subject enrolment options, hence the question.

To answer this question students' mean perception scores were first computed to determine the type of perception students held generally about the subject and their perception based on differences in characteristics such as gender, and where those differences existed whether they were significant to give a stereotypic dimension to such perceptions. Discovering the type of perception students held then provided the basis for determining how such perceptions influenced their enrolment decision, by calculating the correlation between students mean perceptions and enrolment to quantify the influence of such perceptions on enrolment. This approach reflects the underlying assumption of qualitative paradigm to understand a phenomenon in as much detail as possible and also making the result statistically defensible.

The research data which answered the question were students' perception scores on 4 negatively worded items on characterization of physical science to which students were to agree on a five point Likert scale. To make the interpretation of general rating of the items meaningful and comparable to other variables with positive items, the scoring of the items were reversed compared to scoring positive statements, with strong agreement to the items attracting the least value (Kubiszyn \& Borich, 2000).

The result (Tables $2-5$ ) shows that the perception of students about physics was generally unfavourable with overall mean value of 1.19. An overall unfavourable perception was also found for all groups; male and female, physical science and biological science students. The overall mean for female students was 1.11 with mean values ranging from 1.07 to 1.16 , while the overall mean for males was 1.22 with mean values ranging from 1.07 to 1.52 . It is important not to interpret an 'unfavourable' perception of physics as it is used here as a derogatory attribution but rather a concession of its nature in discouraging students to enroll in it as a course and a university major.

Table 2 Male and female students' perception of Physics as a subject $(\mathrm{N}=216)$

\begin{tabular}{|c|c|c|c|c|}
\hline \multirow[b]{2}{*}{ Item } & \multicolumn{2}{|c|}{ Score } & \multirow[b]{2}{*}{ Total } & \multirow[b]{2}{*}{ Score Mean } \\
\hline & Male & Female & & \\
\hline Physical is a difficult subject & 224 & 79 & 303 & 1.4028 \\
\hline Physics is content focused & 166 & 74 & 240 & 1.1111 \\
\hline Physics content is full of abstract ideas & 169 & 80 & 249 & 1.1528 \\
\hline Physics has only a strategic value & 158 & 74 & 232 & 1.0741 \\
\hline Total & 717 & 307 & 1024 & $1.1852 *$ \\
\hline
\end{tabular}

All the mean values were lower than the mid-point value of 3 . These low values match up to unfavourable perception about the nature of physics being held by most students. The perception that physics has only a strategic value seems to be most dominant among students because it has the lowest score for both male and female students, followed by physics being 
content focused and full of abstract ideas. Unexpectedly, the perception that physics is difficult seemed to be the least prevailing perception among students with the highest score for males and the second highest for females. The unexpectedness originates from the fact that many previous research works (Ainley, 1993; Barnes, 1999; Osborne, Driver \& Simon, 1998) identified students' perception of physics to be a difficult subject as the single most compelling reason why students avoid physical science. This surprising result was investigated during the qualitative data collection and analysis.

Likewise, a generally unfavourable perception was discovered among students on the basis of the courses they enrolled in (result presented in Table 3). The mean score for physical science students ranged from 1.09 to 1.58 with an overall mean of 1.24. The overall mean score for biological science students was 1.17 with mean score values ranging from 1.06 to 1.40.

Table 3 Scores of students on perception of Physics as a subject based on their subject area $(\mathrm{N}=216)$

\begin{tabular}{lcccc}
\hline Factor & \multicolumn{3}{c}{ Score } & \\
& Physical Sc. & Biological Sc. & Total & Mean Score \\
\hline Physics is a difficult subject & 104 & 199 & 303 & 1.4028 \\
Physics is content focused & 70 & 170 & 240 & 1.1111 \\
$\begin{array}{l}\text { Physics content is full of abstract } \\
\text { ideas }\end{array}$ & 76 & 173 & 249 & 1.1528 \\
Physics has only a strategic value & 77 & 159 & 236 & 1.0926 \\
Total & 327 & 701 & 1028 & $1.1898^{*}$ \\
\hline
\end{tabular}

Again, the perception of physics having only a strategic value had the least mean score even though it had the second highest rating by physical science students, which somehow seemed to be drowned by its lowest ratings by biological science students. This implied most students strongly agreed physics has strategic value. Also the difficult nature of physics as a subject seemed to be the least perceived by both groups of students with the highest mean perception value of 1.52 (corrected to 2 decimal places).

To ascertain whether a statistically significant difference in perception existed among students on the basis of gender and their course of study, a t-test analysis was carried out on their mean perception scores. The result (Table 4 and 5) showed no significant difference in students' perception of physics generally, but on the perception that physics is difficult, for both male and females as well as for physical science and biological science students.

Table 4 Mean and Standard Error Scores of Students' on Perception of Physics by Gender

\begin{tabular}{lccccc}
\hline Factor & $\begin{array}{c}\text { Male }(\mathrm{n}=147) \\
\text { Mean }(\mathrm{SE})\end{array}$ & $\begin{array}{c}\text { Female }(\mathrm{n}=69) \\
\text { Mean }(\mathrm{SE})\end{array}$ & $\mathrm{t}$ & $\mathrm{P}_{0.05}$ \\
\hline Physics is a difficult subject & $1.5238 \pm 0.04133$ & $1.1449 \pm 0.04269$ & \pm 6.376 & $(0.01) \mathrm{S}$ \\
Physics is content focused & $1.1293 \pm 0.02776$ & $1.0725 \pm 0.03144$ & \pm 1.354 & $\mathrm{NS}$ & $\mathrm{NS}$ \\
Physics content is full of abstract ideas & $1.1497 \pm 0.02952$ & $1.1594 \pm 0.04439$ & \pm 0.185 & $\mathrm{NS}$ \\
Physics has only a strategic value & $1.0952 \pm 0.02949$ & $1.0870 \pm 0.03417$ & \pm 0.169 & $\mathrm{NS}$
\end{tabular}

Table 5 Mean and Standard Error Scores of Students on perception of physics by course of study

\begin{tabular}{lccccc} 
& $\begin{array}{c}\text { Physical Science } \\
\text { students }(\mathrm{n}=66) \\
\text { Fean }(\mathrm{SE})\end{array}$ & $\begin{array}{c}\text { Biological Science } \\
\text { Students }(\mathrm{n}=150) \\
\text { Mean }(\mathrm{SE})\end{array}$ & $\mathrm{t}$ & $\mathrm{P}_{0.05}$ \\
\hline Physics is a difficult subject & $1.5758 \pm 0.06130$ & $1.3267 \pm 0.03842$ & \pm 3.520 & $(0.01) \mathrm{S}$
\end{tabular}


Physics is content focused

Physics content is full of abstract ideas

Physics has only a strategic value

$\begin{array}{llll}1.0606 \pm 0.02960 & 1.1333 \pm 0.02960 & \pm 1.790 & \text { NS } \\ 1.1515 \pm 0.0447 & 1.1533 \pm 0.02952 & \pm 0.32 & \text { NS } \\ 1.1667 \pm 0.05102 & 1.0600 \pm 0.02361 & \pm 1.897 & \text { NS }\end{array}$

The significant difference in perception shown by male students compared to female students as well as biological science students compared to physical science students only on how they rated the difficult nature of physics, among the other factors, presents the need to examine whether the relationship between gender, course of study and students' perception of the course/subject is strong at all, therefore, gender for example could be used to predict a students' perception of physics especially the perception of how difficult they think physics as a subject is. This was done by calculating Cohen's $d$ effect size for the $\mathbf{t}$ test on the perception of difficulty. The effect size was derived by dividing the difference in mean for the two respective groups (male and female; physical science and biological science) by their pooled standard deviation, where the pooled standard deviation was the sum of the standard deviation of the two groups divided by two $[\mathrm{d}=$ (Mean for group A - Mean for group B / Pooled standard deviation)].

The effect size for gender $=0.89$ while that of course of study $=0.51$. By convention, $a$ strong relationship exists between gender and perception of physics, but a moderate relationship exists between perception and course of study. In other words gender can strongly predict students perception of physics where as the course of study a student enrolls in can moderately predict his/her perception of physics.

Now, to provide the final phase of the answer to the research question, a correlation coefficient was calculated between mean perception of each student and enrolment. A positive, moderate but very significant correlation $(r=0.349 ; p<0.05)$, signifying a direct relationship between students' perception and physical science enrolment. In the context of the study, because students perception of the subject were generally unfavourable coupled with the relatively low choice of physical science among students, it implied students' perception had negative influence on their physical science enrolment decision. The result therefore showed that students' decision to enroll in physical science is directly influenced by their perception of the subject such that the more unfavourable their perception of the subject the more likely were they to avoid it, but the more favourable their perception, the more likely were they to enroll in the subject. However, whatever their perception, such perception will only moderately influence their decision.

Though the correlation was very significant, students' perception of physics could explain only about $12.2 \%$ of variance in their choice of subject $\left(\mathrm{r}^{2}=0.349^{2,}=0.122\right)$. This however could be artificial due to low correlation caused by restriction of range because; the range of mean perception was 1, 2 and 3 that is, unfavourable, neutral and favourable respectively with most of the scores clustering around 1 and 2 and in terms of enrolment students either enrolled in physics or did not, that is 2 and 1 .

\section{RESEARCH QUESTION 2 How does learners' view about teaching and learning of physics affect their interest in physical science?}

It cannot be disputed that the experience students have with a subject is a function of how such a subject is presented to them. Such experience shapes their perception and eventually their attitude which makes them receptive or apathetic to the subject or parts of the subject. Schreiner and Sjøberg (2004) believe such attitudes are also important determinants for the choice of school subjects. This question was answered using data that sought students' perception of their physics class, on eight science class room characteristics. The ninth item which more or less served as a check on the genuineness of students' response to the 8 items, 
requested them to rate their perception of effectiveness of teaching and learning in the physics classroom from 'very poor' to 'very effective'. This was necessary because of the unwillingness of many students, to respond to items whose interpretation could mean passing judgment on the competence of their lectures during the pilot test. The analysis of the research data similar to that of research question 1, presented in (Tables 6 to 11) includes the determination of overall mean (overall perception) as well as perception based on gender and course of study. A test for differences in perception and correlations were also carried out.

The overall students' perception about their physics classroom was unfavourable for physical science enrolment with an overall mean of 1.3842. The mean for male students was lower than that of female students (1.3767 male; 1.4003 female) with mean score values of males ranging between 1.0408 and 1.9184 while those of females ranged from 1.0870 to 2.2174 (see Table 6). The item on the strategic use of learning technology to increase the effectiveness of student' learning was given the lowest rating by both groups of students. Male and female students gave the 'perception of the physics class engaging students actively with concepts' high ratings just as the 'perception of the physics class providing individual attention'. Though students' perceptions were generally unfavourable, the fact that they agree more with the physics class engaging them actively with concepts and addressing their individual learning needs than being 'encouraged to develop meaningful understanding' produced somewhat a discrepant finding. Can a student feel relatively actively engaged and his/her individual learning needs addressed but still not develop a meaningful understanding of the concept relative to the level of engagement and the extent to which they feel their learning needs met?

Table 6 Scores of students on perception of physics class/lecture room by gender $(\mathrm{N}=216)$

\begin{tabular}{|c|c|c|c|c|}
\hline \multirow[b]{2}{*}{ Item } & \multicolumn{2}{|c|}{ Score } & \multirow[b]{2}{*}{ Total } & \multirow{2}{*}{$\begin{array}{l}\text { Mean } \\
\text { Score }\end{array}$} \\
\hline & Male & Female & & \\
\hline Active student engagement with concepts & 277 & 153 & 430 & 1.9907 \\
\hline Students encouraged to develop meaningful understanding & 187 & 89 & 276 & 1.2778 \\
\hline Ideas in Physics linked to students' everyday life and interest & 183 & 82 & 265 & 1.2269 \\
\hline Students individual learning needs and preferences catered for & 282 & 128 & 410 & 1.8981 \\
\hline $\begin{array}{l}\text { Use of various assessment techniques to reflect different types } \\
\text { of understanding }\end{array}$ & 159 & 76 & 235 & 1.0880 \\
\hline $\begin{array}{l}\text { Physics content presented to depict science as a human } \\
\text { construct }\end{array}$ & 199 & 87 & 286 & 1.3241 \\
\hline Physics class linked to the broader community & 179 & 83 & 262 & 1.2130 \\
\hline $\begin{array}{l}\text { Use of learning technologies strategically to increase } \\
\text { effectiveness of student learning }\end{array}$ & 153 & 75 & 228 & 1.0556 \\
\hline Total & 1619 & 773 & 2392 & $1.3842 *$ \\
\hline
\end{tabular}

Perception remained unfavourable among both biological and physical science students (Table 7) with mean perception scores varying between 1.0152 to 2.2121 for physical science students and 1.0733 to 1.8933 for biological science students, and an overall mean perception of 1.4067. Again, both group of students gave 'the use of learning technologies strategically to increase effectiveness of student learning' and 'the use of various assessment techniques to reflect different types of understanding' the lowest ratings, and 'active student engagement with concepts' in the physics class/lecture room the highest rating.

Table 7 Scores of biology and physics students on perception of physics class/lecture room

\begin{tabular}{|l|l|l|l|}
\hline Item & Score & Total & Mean \\
\hline
\end{tabular}




\begin{tabular}{|c|c|c|c|c|}
\hline & Phy. Sc. & Bio. Sc & & Score \\
\hline Active student engagement with concepts & 146 & 284 & 430 & 2.0527 \\
\hline Students encouraged to develop meaningful understanding & 86 & 190 & 276 & 1.2848 \\
\hline Ideas in Physics linked to students everyday life and interest & 82 & 183 & 265 & 1.2234 \\
\hline Students individual learning needs and preferences catered for & 149 & 261 & 410 & 1.9988 \\
\hline $\begin{array}{l}\text { Use of various assessment techniques to reflect different types } \\
\text { of understanding }\end{array}$ & 73 & 162 & 235 & 1.0930 \\
\hline Physics content presented to depict science as a human construct & 199 & 87 & 286 & 1.3241 \\
\hline Physics class linked to the broader community & 179 & 83 & 262 & 1.2212 \\
\hline $\begin{array}{l}\text { Use of learning technologies strategically to increase } \\
\text { effectiveness of student learning }\end{array}$ & 153 & 75 & 228 & 1.0556 \\
\hline Total & 1619 & 773 & 2392 & $1.4067 *$ \\
\hline
\end{tabular}

Though perceptions about the physics class was generally unfavourable, a t-test analysis (Tables 8 and 9) showed students differ significantly on 'the perception of physics class actively engaging students with concepts' for male and female students as well as for physical and biological science students.

Table 8 Mean and standard error scores of students on perception of the physics class by gender

\begin{tabular}{|l|l|l|l|l|}
\hline Factor & $\begin{array}{c}\text { Male (n=147) } \\
\text { Mean (SE) }\end{array}$ & $\begin{array}{c}\text { Female (n=69) } \\
\text { Mean (SE) }\end{array}$ & t & \multicolumn{1}{|c|}{$\mathrm{P}_{0.05}$} \\
\hline Active student engagement with concepts & $1.8844 \pm .07062$ & $2.2174 \pm .08225$ & \pm 3.072 & $(.002) \mathrm{S}$ \\
\hline $\begin{array}{l}\text { Students encouraged to develop meaningful } \\
\text { understanding }\end{array}$ & $1.2721 \pm .05159$ & $1.2899 \pm .06879$ & \pm 0.200 & $\mathrm{NS}$ \\
\hline $\begin{array}{l}\text { Ideas in Physics linked to students everyday } \\
\text { life and interest }\end{array}$ & $1.2449 \pm .04689$ & $1.1884 \pm .04742$ & \pm 0.745 & $\mathrm{NS}$ \\
\hline $\begin{array}{l}\text { Students individual learning needs and } \\
\text { preferences catered for }\end{array}$ & $1.9184 \pm .07257$ & $1.8551 \pm .11360$ & \pm 0.482 & $\mathrm{NS}$ \\
\hline $\begin{array}{l}\text { Use of various assessment techniques to } \\
\text { reflect different types of understanding }\end{array}$ & $1.0816 \pm .02266$ & $1.1014 \pm .04203$ & \pm 0.452 & $\mathrm{NS}$ \\
\hline $\begin{array}{l}\text { Physics content presented to depict science as } \\
\text { human construct }\end{array}$ & $1.3537( \pm .06241)$ & $1.2609( \pm .05325)$ & \pm 1.132 & $\mathrm{NS}$ \\
\hline $\begin{array}{l}\text { Physics class linked to the broader } \\
\text { community }\end{array}$ & $1.2177 \pm .03803$ & $1.2029 \pm .05296$ & \pm 0.223 & NS \\
\hline $\begin{array}{l}\text { Use of learning technologies strategically to } \\
\text { increase effectiveness of student learning }\end{array}$ & $1.0408 \pm .02132$ & $1.0870 \pm .03417$ & \pm 1.146 & NS \\
\hline
\end{tabular}

Table 9 Mean and standard error of students on perception of physics class by course of study

\begin{tabular}{|c|c|c|c|c|}
\hline Factor & $\begin{array}{l}\text { Physics students } \\
(\mathrm{n}=150) \text { Mean } \\
\text { (SE) }\end{array}$ & $\begin{array}{c}\text { Biology } \\
\text { students }(n= \\
\text { 66) } \operatorname{Mean}(\mathrm{SE})\end{array}$ & $\mathbf{t}$ & $\mathbf{P}_{0.05}$ \\
\hline Active student engagement with concepts & $2.2121 \pm .08226$ & $1.8933 \pm .07025$ & \pm 2.947 & $(.004) \mathrm{S}$ \\
\hline $\begin{array}{l}\text { Students encouraged to develop meaningful } \\
\text { understanding }\end{array}$ & $1.3030 \pm .07470$ & $1.2667 \pm .04976$ & \pm 0.404 & NS \\
\hline $\begin{array}{l}\text { Ideas in Physics linked to students everyday } \\
\text { life and interest }\end{array}$ & $1.2424 \pm .06849$ & $1.2200 \pm .04109$ & \pm .292 & NS \\
\hline
\end{tabular}




\begin{tabular}{|l|l|l|l|l|}
\hline $\begin{array}{l}\text { Students individual learning needs and } \\
\text { preferences catered for }\end{array}$ & $2.2576 \pm .11284$ & $1.7400 \pm .06915$ & \pm 4.034 & $\begin{array}{l}\text { (.000) } \\
\text { S }\end{array}$ \\
\hline $\begin{array}{l}\text { Use of various assessment techniques to } \\
\text { reflect different types of understanding }\end{array}$ & $1.1061 \pm .03819$ & $1.0800 \pm .02415$ & \pm .588 & NS \\
\hline $\begin{array}{l}\text { Physics content presented to depict science as } \\
\text { human construct }\end{array}$ & $1.2273 \pm .06403$ & $1.3667 \pm .05939$ & \pm 1.596 & NS \\
\hline $\begin{array}{l}\text { Physics class linked to the broader } \\
\text { community }\end{array}$ & $1.2424 \pm .06130$ & $1.2000 \pm .03539$ & \pm .633 & NS \\
\hline $\begin{array}{l}\text { Use of learning technologies strategically to } \\
\text { increase effectiveness of student learning }\end{array}$ & $1.0152 \pm .01515$ & $1.0733 \pm .02520$ & \pm 1.479 & NS \\
\hline
\end{tabular}

Physical science students also differ significantly from biological science students on the perception of physics class 'addressing individual learning needs and preferences of students'. In spite of the generally unfavourable perception students hold about their physics class they rather unexpectedly, in the face of the low mean scores of the individual items on perception, gave 'effective' rating to teaching and learning in their physics classes/lectures.

Table 10 Student ratings of the effectiveness of Physics teaching and learning by gender

\begin{tabular}{|l|c|c|c|c|}
\hline Gender of Student & Number $^{\mathbf{1}}$ & Ratings $^{\mathbf{2}}$ & Mean Rating & Std. Deviation \\
\hline Male & 142 & 558 & 3.9296 & 0.30708 \\
Female & 63 & 249 & 3.9524 & 0.21467 \\
Total & 205 & 807 & 3.9366 & 0.28159 \\
\hline
\end{tabular}

${ }^{1}$ Number of students $=216 ;{ }^{2}$ Eleven students did not give any rating

Table 11 Student ratings of the effectiveness of Physics teaching and learning by course

\begin{tabular}{|l|c|c|c|c|}
\hline \multicolumn{1}{|c|}{ Course of Study } & Number $^{\mathbf{1}}$ & Ratings $^{\mathbf{2}}$ & Mean Rating & Std. Deviation \\
\hline Physical Science & 59 & 233 & 3.9492 & 0.34360 \\
Biological Science & 146 & 574 & 3.9315 & 0.25346 \\
Total & 205 & 807 & 3.9366 & 0.28159 \\
\hline
\end{tabular}

${ }^{1}$ Number of students $=216 ;{ }^{2}$ Eleven students did not give any rating.

Tables 10 shows female and physics students rated their physics class higher than male and biology students respectively. The overall mean scores were more on the side of an 'effective' rating contrary to the low level of perception. This is a seemingly anomalous result.

Against the backdrop of the low mean scores on both students' perception of physics and their physics class, and the similarity in the clustering of the scores judging from the respective mean scores and standard deviations, the result from finding correlation between perception of the physics class and enrolment (as was done in research question 1) looks obvious, that is, a correlation which implies students generally had unfavourable view of the physical science class which do not generally inspire their engagement with the subject. I therefore thought it more useful in finding out any relationship between students' perception of the physics subject and their perception of the physics class, and if they are related, find out how the constituent factors (various science class room characteristics) were interacting to shape students' attitude towards the subject. This will help to examine the question of whether physics as a subject has inherent features, which direct how it is presented to learners and makes it unattractive to students or it, is the physics classroom that has crafted an unattractive image for physics.

Spearman's correlation coefficient was used to determine associations between the variables 
(equivalent to Pearson's correlation coefficient for parametric data). Standard levels of significance were $p<0.05$ and $p<0.01$, while correlation values should fall within the range +1 to -1 , with 0 representing no correlation (Bryman \& Cramer, 2001). Almost all the items on 'perception of physics' correlated positively with almost all items on 'perception of the physics classroom' (Table 12), though, it was not all of them that showed significant correlations. This means students who had low scores for the first variable had equally low score for the second variable. Because the items on the first variable (perception of physics) were negatively worded compared to the items on the second variable (perception of the physics classroom) which were positively worded, this implied most students who agreed with the negative statements about the nature of physics also disagreed with the positive statements on the physics classroom. 
Table 12 Correlations between questionnaire items on students' perception of physics and their physics classroom

\begin{tabular}{|c|c|c|c|c|c|c|c|c|c|c|c|}
\hline Factor & 1B & $1 C$ & 1D & $2 A$ & $2 B$ & $2 \mathrm{C}$ & $2 \mathrm{D}$ & $2 E$ & $2 \mathrm{~F}$ & $2 G$ & $2 \mathrm{H}$ \\
\hline \multicolumn{12}{|l|}{ Physics is difficult } \\
\hline Content focused & $260^{*}$ & & & & & & & & & & \\
\hline Full of abstract ideas & $-.139^{*}$ & $.587^{*}$ & & & & & & & & & \\
\hline Has only strategic value & -.062 & .112 & $.209^{*}$ & & & & & & & & \\
\hline Active student engagement & $-.327^{*}$ & $.310^{*}$ & $.524^{*}$ & .190 & & & & & & & \\
\hline Meaningful understanding & -.074 & $.481^{*}$ & $.790^{*}$ & .128 & $.466^{*}$ & & & & & & \\
\hline Linked to everyday interest & & -.112 & $.485^{\star}$ & $.761^{*}$ & $.239^{*}$ & $.499 *$ & $.798^{*}$ & & & & \\
\hline Addresses individual needs & .045 & .088 & $.384^{*}$ & $.181^{*}$ & $.462^{*}$ & $.295^{*}$ & $.341^{*}$ & & & & \\
\hline Uses various assessments & .092 & .110 & $.386^{*}$ & $.227^{*}$ & .127 & $.290^{*}$ & $.184^{*}$ & $.209^{*}$ & & & \\
\hline Depicted as human construct & -.068 & $.355^{\star}$ & $.507^{\star}$ & $187^{*}$ & $.287^{*}$ & $.632^{*}$ & $.653^{*}$ & $.173^{*}$ & -.119 & & \\
\hline Linked to broader community & -.108 & $.446^{*}$ & $.728^{*}$ & $.238^{*}$ & $.543^{*}$ & $.789^{*}$ & $.899^{*}$ & $.347^{*}$ & .141 & $.688^{*}$ & \\
\hline Uses technologies for effective student learning & $.224^{*}$ & -.078 & -.033 & .016 & $-.214^{*}$ & -.062 & -.052 & -.073 & -.066 & -.075 & -.054 \\
\hline
\end{tabular}

(Significant Spearman's correlation coefficient ' $r$ '; ${ }^{*} p<0.05 ;{ }^{*} p<0.01$ ) 
Despite almost all the items correlated positively with each other, negative correlations were peculiarly observed between almost all items, and items 1A (Physics is a difficult subject) and $2 \mathrm{H}$ (Uses technologies for effective student learning). For ' $1 \mathrm{~A}$ ' the negative correlations could be due to the 'unexpected' relatively high students score on perception of difficulty. The negative correlation between ' $2 \mathrm{H}$ ' and other factors, and its apparent lack of significant correlation with most factors (evident in the result in table 4-13) could have been occasioned by the fact that almost all students strongly disagreed with the positive statement on the use of learning technology in the physics classroom. A strong disagreement with the statement attracted the lowest score $(=1)$ while a lot of the scores on the other items were comparatively higher, and because Spearman's rho calculates correlation coefficient on rankings ( rho $=1-$ $\left[\left(6 * \operatorname{SUM}\left(d^{2}\right) / n\left(n^{2}-1\right)\right]\right.$ where $d=$ the difference in ranks and $n$ is the sample size $)$ but not the data itself as Pearson's $r$ does on parametric data, any such calculation will produce no correlation or negative correlation which does not necessarily mean a no or inverse relationship.

Although these correlations were discussed in detail in chapter five (5), the result shows that, for example, most students who thought physics content is full of abstract ideas (Factor 1C) also felt the physics classroom does not actively engage them $(2 \mathrm{~A})(\mathrm{r}=0.524, \mathrm{p}<0.01)$; they were not encouraged to develop meaningful understanding (2B) $(r=0.790, p<0.01)$; physics content is not linked to their everyday needs and interest $(2 \mathrm{C})(r=0.761, p<0.01)$; addresses their individual learning needs (2D); neither is it presented to depict science as human construct $(2 \mathrm{~F})(r=0.507, p<0.01)$ nor linked to the broader society $(2 \mathrm{G})(r=0.728, p<0.01)$. There was as well significant relationship between students' perception that physics is difficult (1A) and learning technologies not being strategically used to increase the effectiveness of students' learning $(2 \mathrm{H})(r=-0.224, p<0.01)$.

\section{Conclusion}

Although the study probed all four worlds of the students for potential and 'real' influences within them which impacts on their deliberations in choosing a science course, the factors most closely associated with decisions for physical science were found within the students' world of school science and peer. The influence of the two worlds appeared to be causing low student enrolment in physical science in the University (UEW). This seemed to be creating a vicious cycle between, lack of physics teachers in the second cycle schools, unpleasant students' experience with physics, low interest in physics at the university, and low turnout of physics graduates.

Students' description of physics strongly supported the four themes about the nature of physics on which their perception was weighed up and went on to possibly explain why those factors were influencing physical science enrolment. The first theme was the description of physics as a subject that focused on facts transmitted from expert sources - teachers and texts, to relatively passive recipients (students), giving it content focused characteristic. Though students differ on this view with physical science compared to biological science students as well as males compared to females giving it slightly different but not significant scoring, majority were critical of it as a default teaching mode. They revealed only few teachers tried to present the content in an engaging manner and such teachers remained in their memories as their best teachers and drew them to physics class all the times.

Finally, physics was conceptualised as a subject having only a primarily strategic value which could prove invaluable in post-graduation opportunities. This is common to the works of Barnes (1999); Fullarton \& Ainley (2000); Osborne \& Collins (2001) and Lyons (2003). The strategic conceptualization of physics was shared by most science students (including biological science students) and consistent with the mean values that shows strong agreement 
even more by biological science students than physical science students (1.0600 biological science ; 1.1667 physical science) in the quantitative analysis. Most students agreed that, the relatively small number of students enrolling in physical science because of the difficulty associated with physics has instilled physical science with strategic, even prestigious value in that it would open unlimited teaching opportunities for the few who had the courage to study it.

The fact that most schools could have qualified biology teachers, but inadequate or no qualified physics teachers could have two consequences, first, teachers may tend to teach to their strengths and at the junior level this could reinforce biology and the predominance of biology classes could encourage students to take biology.

Ghana like most (if not all) developing countries conspicuously lags behind in terms of science and technological development. If this were to change, then the school system must be well resourced with teachers who possess the requisite knowledge and teaching techniques, as well as modern teaching -learning materials. This will enable the school, especially at the basic and second cycle level to play an effective role as a 'womb' for nurturing young scientists, by taking advantage of the high interest learners show in science at those levels in developing countries (Sjøberg, 2000, 2002c).

The future of this nation (Ghana) especially in the area of science and technological development to a large extent seemed to rest in the hands of science students, lecturers and policy makers of UEW, as emerging premier institution purely for teacher training. Therefore conscientious effort must be made to break down barriers to students' interest in science and physics in particular.

\section{References}

Ainley, J. (1993). 'Participation in Science Courses in Senior Secondary School', Research in Science and Technological Education, 11 (2): 207 - 223.

Ainley, J., Robinson, L, Havey - Beavis, A., Elsworth, G., \& Fleming, M., (1994). Subject choice in years 11 and 12. Canberra, ACT: AGPS.

Anamuah-Mensah, J. (1995). Science and Technology Clinics for Girls in Ghana. In UNESCO (1996). Towards Scientific and Technological Literacy for all in Africa. Dakar.

Barnes, G. (1999). 'A Motivational Model of Enrolment Intentions in Senior Secondary Science in New South Wales (Australia) schools' unpublished Thesis. University of Western Sydney, Sydney, NSW.

Bennett, J. (2001). 'Science with Attitude: the Perennial Issue of Pupil's Responses to Science', School Science Review 82 (300): 59 - 67.

Bolstad, R. \& Hipkins, R. (2005). Staying in science: Students' participation in secondary education and on transition to tertiary studies. New Zealand, Wellington: New Zealand Council for Educational Research.

Bordt, M., De Broucker, P. C. Harris S. and Zhang, Y. (2001). Determinants of Science and Technology Skills: Overview, Education Quarterly Review, Statistics Canada, (8) $1: 8-11$.

Bryman, A. and Cramer, D. (2001). Qualitative data analysis with SPSS release 10 for Windows: a guide for social scientists. Hove, UK: Routledge.

Chepchieng M. C (2004). Influence of Institutional Characteristics on Student Attitudes Toward Campus Environment. A Comparative Study of Public and Private 
Universities in Kenya. Unpublished Ph.D Thesis, Egerton University, Njoro.

Dekkers, J. \& De Laeter, J. (2001), 'Enrolment Trends in School Science Education in Australia', International Journal of Science Education, 23 (5): 487 - 500.

Fullarton, S. \& Ainley, J. (2000). Subject Choice by Students in Year 12 in Australian Secondary Schools, LSAT Research Report Number 15, ACER, Camberwell.

Fullarton, S., Walker, M., Ainley, J. \& Hillman, K. (2003). Patterns of participation in

Year12. Camberwell, Victoria: Australian Council for Educational Research.

Gallagher, K..S (2004). Cognitive science and media. Available at pegasus.cc.ucf/gallghr/gallpubs.html.

Garg, K. \& Gupta, B. (2003). 'Decline in Science Education in India: A Case Study at Undergraduate level', Current Science, 84 (9): 1198 - 1201.

Goodrum, D., Hackling, M. \& Rinnie, L. (2001). The Status and Quality of Teaching and Learning of Science in Australian Schools, DETYA Camberra.

Goto, M. (2001). International Bureau for Education (IBE), Science Education for Contemporary Society: Problems, Issues and Dilemmas, Geneva: IBE, UNESCO: 31 -38 .

Jones, M. G., Howe, A. \& Rua, M. J. (2000). Gender differences in students' experiences, interests, and attitudes towards science and scientists. Science Education, 84: 180192.

Kubiszyn, T. \& Borich, G. (2000). Educational Testing and Measurement: Classroom Application and Practice ( $6^{\text {th }}$ ed). New york: John Wiley and sons.

Levy, J. Wubbels, T., Brekelmans, M., \& Morganfield, B., (1997). Language and cultural factors in students' perceptions of teachers communication style. International of Intercultural Relations, 21(1), 29-59.

Lindah, B. (2003). Lust att lära naturvetenskap och teknik? En longitudinell studie om vägen till gymnasiet. [Pupils' responses to school science and technology? A longitudinal study of pathways to upper secondary school] (Diss., Göteborg Studies in Educational Sciences 196).

Lipps, J.H. (1999). Beyond Reason: Science in the Media. Evolution! Facts \& Fallacies. Academic Press, San Diego. Chapter 4, pp. 71-90 .

Lyons, T. (2003). Decisions by science proficient Year 10 students about post-compulsory high school science: A sociocultural exploration. Unpublished PhD thesis. University of New England. Annidale, NSW.

National Science Foundation (US) (2002). Science and Engineering Indicators 2002, online at http://www.nsf.gov/sbe/srs/ seind02/c0/c0s1.htm (accessed March 4, 2004).

Osborne, J. \& Collins, S. (2001). 'Pupils' Views of the Role and Value of Science Curriculum: a Focus Group Study', International Journal of Science Education, 23 (50): $441-467$.

Osborne, J. Driver, R. \& Simon, S. (1998), 'Attitudes of Science: Issues and 3 Concerns', School Science Review, 79 (288): 27 - 33.

Palmer, M. (1999). Science Education in Crisis: Science at Second Level. Paper originally given at the RDS Seminar Science Education in Crisis?, RDS, Dublin, November 
12th. 1999.

Phelan, P., Davidson, A. \& Cao, H. (1991), 'Students' Multiple Works: Negotiating the Boundaries Of Family, Peer and School Cultures', Anthropology and Education Quarterly, 22, pp. $224-250$.

Ramsden, J. (1998). 'Mission Impossible? Can anything be done about Attitudes to Science?' International Journal of Science Education, 20 (2): 125 - 137.

Rutherford, F.J. \& Ahlgren, A. (1990). Science for All Americans. New York: Oxford University Press.

Schreiner, C., and Sjøberg, S. (2004). Sowing the seeds of ROSE. Background, Rationale, Questionnaire Development and Data Collection for ROSE (The Relevance of Science Education) - a comparative study of students' views of science and science education. Acta Didactica.- (4/2004) (ISBN 82-90904-79- 7): Dept. of Teacher Education and School Development. University of Oslo, Norway.

Smithers, A. \& Robinson, P. (2006). Physics in schools and universities (Vol. Patterns and Polices). Buckingham: Camichael Press.

Sjøberg, S. (2000). Interesting all children in 'science for all'. In R. Millar, J. Leach \& J. Osborne (Eds.), Improving science education. Buckingham- Philadelphia: Open University Press. 315.

Sjøberg, S. (2002c). Science and technology education in Europe: current challenges and possible solutions. Connect UNESCO (E.W. Jenkins ed), 27(3-4), 1-5.

Whitt, E., Edison, M.I, Pascarella E.T, Terenzini P.T., \& Nora M (2001). Impact of College on Students. J.of Higher Educ.12 (2), pp. 172-204.

Woolnough, B. (1994). 'Factors Affecting Students' Choice of Science and Engineering', International Journal of Science Education, 16 (6): 659 - 676. 